\title{
Analisis Kadar Vitamin C pada Buah Jeruk Menggunakan Metode Titrasi Iodometri
}

\author{
Analysis of Vitamin C Levels in Citrus Fruits Using the Iodometric \\ Titration Method
}

\author{
Yolla Arinda Nur Fitriana ${ }^{1}$, Ardhista Shabrina Fitri ${ }^{2}$ \\ ${ }^{1}$ Teknologi Pangan, Universitas Ahmad Dahlan \\ ${ }^{2}$ Farmasi, Universitas Muhammadiyah Purwokerto \\ 1.yollaanf@gmail.com \\ ${ }^{2}$ ardhista.shabrina.fitri@gmail.com
}

\begin{abstract}
ABSTRAK
Vitamin $C$ sebagai salah satu vitamin yang sangat penting bagi kesehatan tubuh banyak terdapat di berbagai macam buah segar khususnya buah jeruk. Buah jeruk yang sangat digemari masyarakat Indonesia adalah jeruk berastagi dan keprok. Selain warnanya yang cerah, kandungan vitamin $\mathrm{C}$ buah jeruk tergolong tinggi. Vitamin $\mathrm{C}$ atau asam askorbat adalah komponen berharga dalam makanan karena berguna sebagai antioksidan dan mengandung khasiat pengobatan. Karena peran vitamin $C$ sangat penting, maka perlu diketahui kandungan vitamin $\mathrm{C}$ buah jeruk dengan harapan dapat dijadikan acuan dalam memilih buah jeruk sesuai kebutuhan dan selera. Dalam penelitian ini dilakukan analisis kadar vitamin $\mathrm{C}$ menggunakan metode titrasi iodometri. Sampel dalam penelitian ini adalah jeruk berastagi dan jeruk keprok. Hasil analisis diperoleh informasi bahwa kadar vitamin $\mathrm{C}$ jeruk berastagi lebih tinggi dibanding jeruk keprok dengan selisih $0.88 \%$.
\end{abstract}

Kata-kata kunci: titrasi iodometri, vitamin $\mathrm{C}$, jeruk.

\begin{abstract}
Vitamin C, like a vitamin, which is very important for the health of the body, is found in various kinds of fresh fruit, especially citrus fruits. Citrus fruits that are very popular with Indonesians are berastagi and tangerines. Apart from the bright color, the vitamin $C$ content of citrus fruits is relatively high. Vitamin $C$ or ascorbic acid is a valuable component in food because it is useful as an antioxidant and contains medicinal properties. Because the role of vitamin $C$ is crucial, it is necessary to know the vitamin $C$ content of oranges in the hope that it can be used as a reference in choosing citrus fruits according to your needs and tastes. In this study, the analysis of vitamin C levels was carried out using the iodometric titration method. The samples in this study were berastagi oranges and tangerines. The results of the research obtained information that the vitamin $C$ content of berastagi oranges was higher than tangerines with a difference of $0.88 \%$.
\end{abstract}

Keywords: iodometric titration, vitamin $C$, orange.

\section{PENDAHULUAN}

Vitamin $C$ adalah vitamin yang tergolong vitamin yang larut dalam air. Sumber vitamin $\mathrm{C}$ sebagian besar tergolong dari sayur-sayuran dan buah-buahan segar. Asupan gizi rata-rata sehari sekitar 30 sampai $100 \mathrm{mg}$ vitamin C yang dianjurkan untuk orang 
dewasa. Namun, terdapat variasi kebutuhan dalam individu yang berbeda (Sweetman, 2005).

Vitamin $\mathrm{C}$ atau asam askorbat adalah komponen berharga dalam makanan karena berguna sebagai antioksidan dan mengandung khasiat pengobatan (Goodman, 1991). Vitamin C mempunyai banyak fungsi di dalam tubuh. Pertama, fungsi vitamin $\mathrm{C}$ adalah sebagai sintesis kolagen. Asam askorbat penting untuk mengaktifkan enzim prolil hidroksilase, yang menunjang tahap hidroksilasi dalam pembentukan hidroksipolin, suatu unsur integral kolagen. Tanpa asam askorbat, serabut kolagen yang terbentuk di semua jaringan tubuh menjadi cacat dan lemah. Oleh sebab itu, vitamin $\mathrm{C}$ penting untuk pertumbuhan dan kekurangan serabut di jaringan subkutan, kartilago, tulang, dan gigi (Guyton, 2007).

Fungsi yang kedua adalah absorbsi dan metabolisme besi. Vitamin C mereduksi besi menjadi feri dan menjadi fero dalam usus halus sehingga mudah untuk diabsorbsi. Fungsi yang ketiga adalah mencegah infeksi. Vitamin $\mathrm{C}$ berperan dalam meningkatkan daya tahan tubuh terhadap infeksi (Pauling, 1971). Selain itu, penelitian menunjukkan bahwa vitamin $\mathrm{C}$ memegang peranan penting dalam mencegah terjadinya aterosklerosis. Vitamin $\mathrm{C}$ mempunyai hubungan dengan metabolisme kolesterol. Kekurangan vitamin $\mathrm{C}$ menyebabkan peningkatan sintesis kolesterol (Khomsan, 2010).

Jenis jeruk yang banyak digemari masyarakat sebagai asupan vitamin $\mathrm{C}$ adalah jeruk berastagi dan keprok. Jeruk berastagi merupakan jenis jeruk Washington Navel Orange (WNO) yang banyak ditanam di Brastagi, Sumatera Utara. Buahnya berbentuk bulat dengan permukaan agak halus. Daging buahnya bertekstur lunak, mengandung banyak air, dan berwarna kekuningan. Ujung bauh bundar dan berpusar. Rasanya yang manis dan baunya yang harum membuat jeruk berastagi digemari banyak orang. Umumnya, jeruk ini dimakan dalam keadaan segar, namun di Brazil dan Florida 90\% dari produksi diolah menjadi sari buah (Rahmawati, 2015).

Jeruk keprok atau yang juga sering disebut dengan tangerine adalah salah satu jenis jeruk yang paling digemari. Buah jeruk keprok adalah sumber vitamin $\mathrm{C}$ yang kaya. Jeruk keprok juga mengandung folat dan betakaroten. Buah ini memiliki 40 kalori, 1,5 gram serat dan kandungan vitamin A yang lebih besar dari jeruk biasa. Jeruk keprok memiliki beberapa manfaat bagi kesehatan antara lain mengandung vitamin A yang baik untuk kesehatan mata, mengandung vitamin $\mathrm{C}$ dan kalsium yang baik untuk persendian dan juga untuk menjaga tulang tetap kuat, membantu penyeerapan zat besi, dan dapat membantu menyehatkan kulit (Rismarini, 2018).

Analisis kadar vitamin $\mathrm{C}$ biasa menggunakan titrasi dengan iodium. Metode ini paling banyak digunakan karena murah, sederhana, dan tidak memerlukan peralatan laboratorium yang canggih. Titrasi ini memakai iodium sebagai oksidator yang mengoksidasi vitamin C dan memakai amilum sebagai indikatornya (Widjanarko, 2002). Pati atau amilum merupakan karbohidrat kompleks yang tidak larut dalam air, berwujud bubuk putih, tawar, dan tidak berbau. Dalam jumlah besar, pati dihasilkan dari dalam daun-daun hijau sebagai wujud penyimpanan sementara dari produk fotosintesis. Pati juga tersimpan dalam bahan makanan cadangan permanen untuk tanaman, dalam biji, jari-jari teras, kulit batang, akar tanaman menahun, dan umbi (Claus et al., 1970).

Pati memiliki bentuk kristal bergranula yang tidak larut dalam air pada temperatur ruangan yang memiliki ukuran dan bentuk tergantung pada jenis tanamannya. Pati digunakan sebagai pengental dan penstabil dalam makanan. Pati alami menyebabkan beberapa permasalahan yang berhubungan dengan retrogradasi, kestabilan rendah, dan ketahanan pasta yang rendah. Hal tersebut menjadi alasan dilakukan modifikasi pati (Fortuna et al., 2001). 
Iodin adalah salah satu unsur golongan halogen yang berwarna ungu-kehitaman, bersifat korosif, merupakan unsur golongan halogen yang beracun dan memiliki banyak isotop radioaktif. Garam iodin banyak terdapat pada rumput laut. Iod juga ditemukan dalam bentuk cair yang diekstrak dari mineralnya banyak ditemukan di Chile. Iodin memiliki sifat yang hampir sama dengan klorin dan bromin tetapi tidak sereaktif mereka. Iodin bersenyawa dengan banyak unsur lain terutama untuk menyediakan panas dan sebagai katalis kimia (Vernandes, 2017).

Berdasarkan uraian yang telah disebutkan, maka penelitian ini bertujuan untuk mengetahui kadar vitamin C pada sampel jeruk berastagi dan keprok. Manfaat yang diharapkan adalah dengan diketahuinya kadar vitamin $\mathrm{C}$ dari kedua jenis jeruk ini, masyarakat dapat menentukan pilihan jeruk sesuai kebutuhan dalam rangka menambah asupan vitamin yang dibutuhkan tubuh.

\section{METODE}

\section{Alat Dan Bahan}

Alat yang digunakan pada penelitian ini adalah gelas beker, erlenmeyer $250 \mathrm{ml}$, corong, buret dan statif, pipet ukur $10 \mathrm{ml}$, propipet merah, labu ukur $100 \mathrm{ml}$, propipet hijau, timbangan. Bahan yang digunakan pada penelitian ini adalah jeruk berastagi, jeruk keprok, amilum $1 \%$, larutan iod $0,01 \mathrm{~N}$, dan akuades.

\section{Cara Kerja}

Langkah yang dilakukan dalam penelitian ini meliputi tahap pengukuran vitamin $\mathrm{C}$ sampel (Gambar 1) dan pembuatan blanko (Gambar 2).

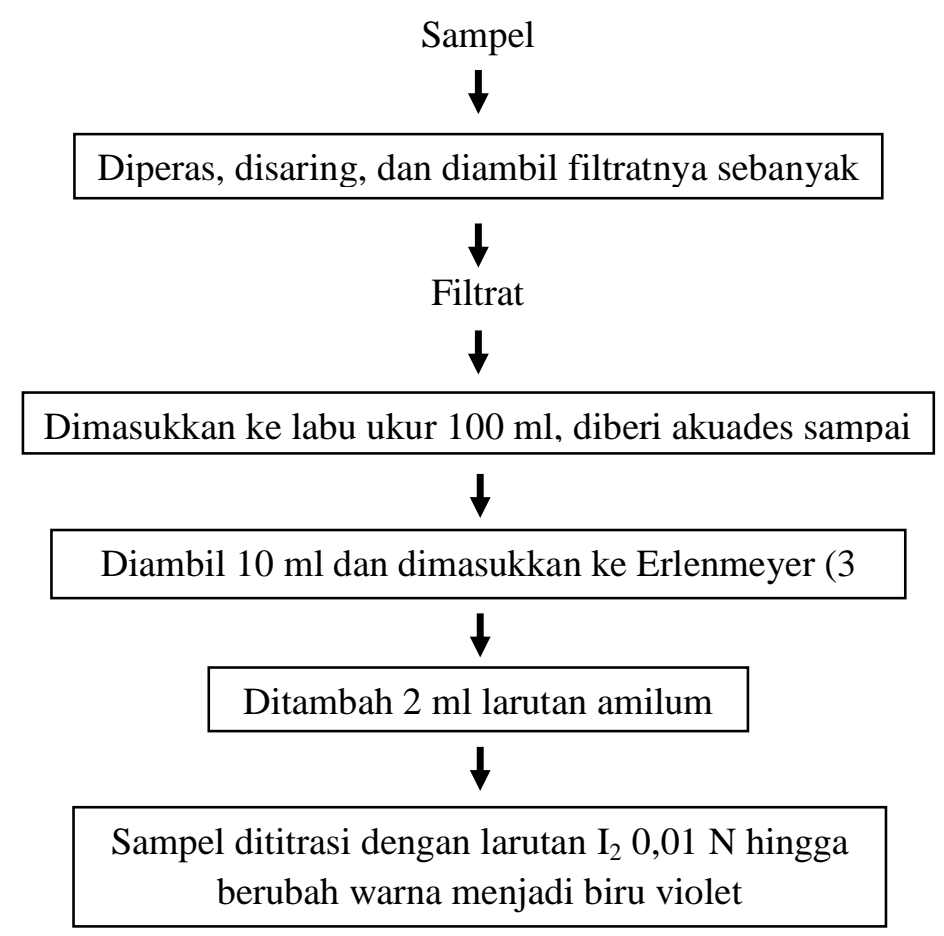

Gambar 1. Pengukuran vitamin C sampel 


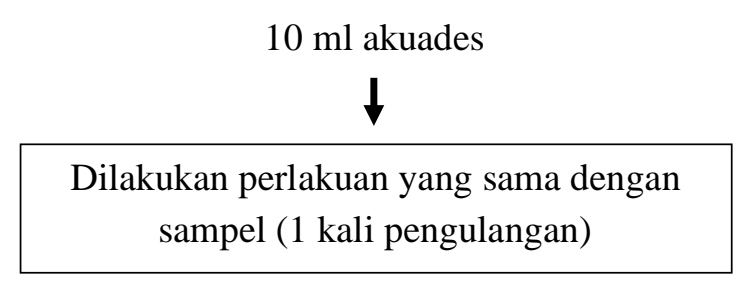

Gambar 2. Pembuatan blanko

Blanko ini merupakan larutan yang mempunyai perlakuan yang sama dengan analat tetapi tidak mengandung komponen analat. Larutan analat adalah larutan yang dianalisis. Tujuan pembuatan larutan blanko ini adalah untuk mengetahui besarnya serapan oleh zat yang bukan analat.

\section{HASIL DAN PEMBAHASAN}

Analisis kadar vitamin $\mathrm{C}$ dalam sampel ini menggunakan metode titrasi iodometri (titrasi langsung). Titrasi ini merupakan titrasi berdasarkan reaksi redoks yang menggunakan larutan beku I2 untuk mengoksidasi analatnya. Iod merupakan oksidator yang tidak terlalu kuat, sehingga hanya zat-zat yang merupakan reduktor yang cukup kuat dapat dititrasi. Indikator yang digunakan ialah amilum, dengan perubahan dari tidak berwarna menjadi biru. Sedangkan vitamin $\mathrm{C}$ dengan iod akan membentuk ikatan dengan atom C nomor 2 dan 3 sehingga ikatan rangkap hilang (Harjadi, 1990).

Indikator amilum merupakan indikator yang sangat lazim digunakan pada saat titrasi iodometri ini. Penentuan titik akhir titrasi dapat terjadi karena terbentuk kompleks amilum I2 yang berwarna biru tua. Hal ini disebabkan karena dalam larutan amilum, terdapat unit-unit glukosa yang membentuk rantai heliks karena adanya ikatan konfigurasi pada tiap unit glukosanya. Bentuk ini menyebabkan amilum dapat membentuk kompleks dengan molekul iodium yang dapat masuk ke dalam spiralnya. Sehingga menyebabkan warna biru tua kompleks tersebut.

Hal pertama yang dilakukan dalam penentuan kadar vitamin $\mathrm{C}$ ini adalah pembuatan larutan iodin $0,01 \mathrm{~N}$ dan amilum $1 \%$. Larutan iodin $0,01 \mathrm{~N}$ dibuat dengan cara menimbang 0,6345 gram iodium dan 2 gram KI, kemudian dimasukkan ke dalam gelas beker dan ditambahkan akuades sebanyak $100 \mathrm{ml}$, diaduk hingga larut. Kemudian larutan tersebut dimasukkan ke dalam gelas labu takar $500 \mathrm{ml}$ dan ditambahi akuades sampai tanda batas dan digojog hingga homogen. Sedangkan untuk amilum 1\%, sebanyak 1 gram amilum dilarutkan dalam akuades sampai volume $100 \mathrm{ml}$. kemudian, larutan tersebut dipanaskan hingga larutan menjadi bening.

Percobaan analisis kadar vitamin $\mathrm{C}$ ini menggunakan sampel jeruk berastagi dan jeruk keprok. Perlakuan pertama yang dilakukan adalah pembuatan filtrat dari perasan jeruk yang disaring. Filtrat tersebut kemudian diencerkan hingga $100 \mathrm{ml}$. Selanjutnya, sampel diambil $10 \mathrm{ml}$ dan dimasukkan ke dalam erlenmeyer dan ditambahkan indikator amilum $1 \%$. Setelah itu dititrasi dengan larutan iodin $0,01 \mathrm{~N}$. proses titrasi dilakukan sampai mencapai titik akhir yaitu perubahan warna dari larutan bening menjadi biru.

Fungsi larutan iod yang digunakan ini adalah untuk memperlihatkan jumlah vitamin $\mathrm{C}$ yang terdapat dalam sampel menjadi senyawa dihidroaskorbat. Sedangkan fungsi amilum adalah untuk membentuk suatu kompleks berwarna biru yang terjadi pada saat bereaksi dengan iodin karena adanya iodida. Larutan amilum tidak boleh ditambahkan tepat sebelum titik akhir dicapai atau pada saat konsentrasi iod tinggi, karena sedikit iod akan tetap teradsobsi bahan pada titik akhir titrasi. Hasil pengukuran kadar vitamin $\mathrm{C}$ dari kedua sampel jeruk disajikan pada Tabel 1. 
Tabel 1. Hasil pengukuran kadar vitamin $\mathrm{C}$

\begin{tabular}{ccccc}
\hline Sampel & $\begin{array}{c}\text { Volume } \\
\text { Titrasi (ml) }\end{array}$ & $\begin{array}{c}\text { Volume } \\
\text { Sampel (ml) }\end{array}$ & \% Vitamin C & $\begin{array}{c}\text { Rerata \% } \\
\text { Vitamin C }\end{array}$ \\
\hline \multirow{2}{*}{ Jeruk } & 1,6 & 10 & 13,21 & \\
Berastagi & 1,6 & 10 & 13,21 & \multirow{2}{*}{13,21} \\
& 1,6 & 10 & 13,21 & \\
\cline { 2 - 4 } Jeruk Keprok & 1,5 & 10 & 12,33 & \multirow{2}{*}{12,33} \\
& 1,5 & 10 & 12,33 & \\
\cline { 2 - 4 } Blanko & 1,5 & 10 & 12,33 & \\
\hline
\end{tabular}

Percobaan analisis kadar vitamin $\mathrm{C}$ ini menghasilkan kadar vitamin $\mathrm{C}$ dari jeruk berastagi adalah $13,21 \%$ atau $13,21 \mathrm{mg} / 100$ gram. Sedangkan pada jeruk keprok adalah $12,33 \%$ atau $12,33 \mathrm{mg} / 100$ gram. Hasil tersebut memiliki selisih jauh dari kandungan vitamin C menurut (Pracaya, 2003) yaitu sekitar 40-70 mg/100 gram pada jeruk. Hal tersebut mungkin terjadi pada saat proses ekstraksi yang memakan waktu cukup lama sehingga menurunkan kadar vitamin $\mathrm{C}$ pada jeruk.

\section{KESIMPULAN}

Kesimpulan dari penelitian ini adalah rerata kadar vitamin $\mathrm{C}$ pada sampel jeruk berastagi adalah $13,21 \%$ sedangkan rerata kadar vitamin $\mathrm{C}$ pada sampel jeruk keprok adalah $12,33 \%$ atau memiliki selisih sebesar $0.88 \%$. Pada penelitian selanjutnya disarankan untuk menganalisis kadar vitamin buah yang lain sehingga mendapatkan informasi yang lebih banyak yang dibutuhkan oleh masyarakat.

\section{DAFTAR PUSTAKA}

Claus, E. P., Tyler, V. E., \& Brady, L. R. (1970). Pharmacognosy. Lea \& Febiger.

Fortuna, T., Juszczak, L., \& Palasinski, M. (2001). Properties of corn and wheat starch phosphates obtained from granules segregated according to their size. Electronic Journal of Polish Agricultural Universities, 4(2), 417-419.

Goodman, S. (1991). Vitamin C, the master nutrient. Keats Publishing.

Guyton, A. C. (2007). Biokimia untuk Pertanian. Universitas Sumatera Utara Press.

Harjadi, W. (1990). Ilmu Kimia Analitik Dasar. Gramedia.

Khomsan, A. (2010). Pangan dan Gizi untuk Kesehatan. Rajagrafindo Persada.

Pauling, L. (1971). General Chemistry (4th ed.). Gaya Baru.

Pracaya. (2003). Jeruk Manis Varietas, Budidaya, dan Pascapanen. Penebar Swadaya.

Rahmawati, A. A. D. (2015). Jeruk Pontianak dan Jeruk Berastagi, Jeruk Lokal Populer yang Manis Segar. Https://Food.Detik.Com/Info-Kuliner/d-3064511/JerukPontianak-Dan-Jeruk-Berastagi-Jeruk-Lokal-Populer-Yang-Manis-Segar. https://food.detik.com/info-kuliner/d-3064511/jeruk-pontianak-dan-jerukberastagi-jeruk-lokal-populer-yang-manis-segar

Rismarini, P. (2018). Cari Tahu Manfaat dari Jeruk Keprok, Bagus Banget Buat Cewek nih, Penasaran? Https://Www.Grid.Id/Read/04620620/Cari-Tahu-Manfaat-DariJeruk-Keprok-Bagus-Banget-Buat-Cewek-Nih-Penasaran?Page=all. https://www.grid.id/read/04620620/cari-tahu-manfaat-dari-jeruk-keprok-bagusbanget-buat-cewek-nih-penasaran?page=all 
Sweetman, S. C. (2005). Martindale: The Complete Drug Reference (34th ed.). Pharmaceutical Press.

Vernandes, A. (2017). Iodin (I) : Sifat, Penemuan, Sumber, Reaksi fan Kegunaannya. Https://Www.Avkimia.Com/2017/03/Iodin-i-Sifat-Penemuan-Sumber-Reaksi-DanKegunaannya.Html. https://www.avkimia.com/2017/03/iodin-i-sifat-penemuansumber-reaksi-dan-kegunaannya.html

Widjanarko, Simon B. (2002). Analisa Hasil Pertanian. Universitas Brawijaya. 